\title{
Phosphogypsum Conversion into Calcium Fluoride and Sodium Sulfate
}

\author{
Yassine Ennaciri*, Mohammed Bettach, Hanan El Alaoui-Belghiti \\ Laboratory of Physical Chemistry of Materials (LPCM), Faculty of Sciences, Chouaib Doukkali University, Route \\ Ben Maachou, B.P. 20 Avenue des Facultés, El Jadida 24000, Morocco
}

Corresponding Author Email: yassinemaster@gmail.com

https://doi.org/10.18280/acsm.440606

Received: 20 December 2019

Accepted: 6 November 2020

\section{Keywords:}

phosphogypsum, sodium fluoride, calcium fluoride, sodium sulfate, wet conversion

\begin{abstract}
The phosphoric acid production in the world generates a large amount of phosphogypsum beside the emission of toxic acid fluorine gas into the atmosphere, which can cause a several environmental problems. To remedying these problems, an environmental procedure permit recycling phosphogypsum waste by $\mathrm{NaF}$ into valuable products, was presented in this work. According the obtained results, the proposed process is feasible and leads preparing a relatively pure $\mathrm{CaF}_{2}$ and $\mathrm{Na}_{2} \mathrm{SO}_{4}$. This last is recommended in detergent and glass industry, while the resulting $\mathrm{CaF}_{2}$ can be utilized in metallurgical industry. The optimum conversion conditions were achieved with the exact stoichiometric phosphogypsum and $\mathrm{NaF}$ at reaction duration of 90 minutes under room temperature.
\end{abstract}

\section{INTRODUCTION}

Phosphogypsum (PG) is an acidic by-product resulted during the production of phosphoric acid by the wet process. This latter can be expressed by the following chemical reaction [1]:

$$
\begin{gathered}
\mathrm{Ca}_{5} \mathrm{~F}\left(\mathrm{PO}_{4}\right)_{3}+5 \mathrm{H}_{2} \mathrm{SO}_{4}+10 \mathrm{H}_{2} \mathrm{O} \rightarrow 5 \mathrm{CaSO}_{4} \cdot 2 \mathrm{H}_{2} \mathrm{O}+ \\
3 \mathrm{H}_{3} \mathrm{PO}_{4}+\mathrm{HF}
\end{gathered}
$$

For one ton of phosphoric acid produced about 3 to 5 tons of PG are generated, with the worldwide PG generation estimated to be around $280 \mathrm{Mt}$ annually. The totality of this quantity is stored in open air $(28 \%)$ or dumped into water bodies (58\%). Although, PG is mainly formed by calcium sulfate (effectively dihydrate) beside numerous impurities such as: phosphates, fluorides, heavy metals, and radioelements. Hence, the presence of these impurities at higher than natural levels, can cause a severe environmental problem in long term [1-3].

In addition, during the phosphoric acid process, the fluoride released as hexafluosilicic acid $\mathrm{H}_{2} \mathrm{SiF}_{6}$ (FSA) is recuperated by $\mathrm{NaOH}$ solution or water to obtain sodium fluoride $(\mathrm{NaF})$ or anhydrous hydrofluoric acid (AHF) respectively $[4,5]$. Ennaciri et al. [6, 7] have discussed and detailed very well the fluorine recovery process during the production of phosphoric acid and the phosphates fertilizers. According to these results, the estimated price of $\mathrm{CaF}_{2}$ (fluorspar) and $\mathrm{NaF}$ were 260-280 \$/ton and 600-640 \$/ton respectively.

Several researches focused to reuse or to valorize the PG in different domains. The possibilities of using PG can be separated into three categories: agricultural application, building materials and raw material for chemical processes.

PG, like gypsum, can be used in the agricultural soils. It increases the acidity of these soils and improves its properties by adding the sulfate and the calcium. However, the PG use in this domain can pose certain problems such as the increase of the hazardous metals and the radioelements level in these soils [8].

At present, the major part of PG is valued in the plaster manufacture and in the cement composition. However, the use of PG in these sectors requires an adequate treatment, in order to improve the setting time, the consistency and the resistance of the plaster and the cement prepared from this residue [9].

PG can be utilized as a raw material for certain chemical production processes. The best known of these processes is the PG thermal decomposition, which permit recovering $\mathrm{SO}_{2}$ gas necessary for the sulfuric acid $\left(\mathrm{H}_{2} \mathrm{SO}_{4}\right)$ production [10].

In recent years, the wet conversion of the PG by ammonium or alkaline compounds remains more sustainable and represents an economical pathway. In addition, the products obtained by this pathway are very interesting for the agriculture, the industry, and the environment.

Several researchers indicated that the possibility to produce potassium sulfate $\left(\mathrm{K}_{2} \mathrm{SO}_{4}\right)$ from the conversion of $\mathrm{PG}$ and potassium chloride $(\mathrm{KCl})$. The basic reaction describing this process is [11]:

$$
\mathrm{CaSO}_{4} \cdot 2 \mathrm{H}_{2} \mathrm{O}+2 \mathrm{KCl} \rightarrow \mathrm{CaCl}_{2}+\mathrm{K}_{2} \mathrm{SO}_{4}+2 \mathrm{H}_{2} \mathrm{O}
$$

Generally, this process needs specific conditions such as: the decrease of temperature and the addition of solvents (ammonia, alcohol) to prevent the formation of undesired complex salts (syngenite $\mathrm{K}_{2} \mathrm{Ca}\left(\mathrm{SO}_{4}\right)_{2} \cdot \mathrm{H}_{2} \mathrm{O}$ and pentasulfate $\mathrm{K}_{2} \mathrm{SO}_{4} .5 \mathrm{CaSO}_{4} \cdot \mathrm{H}_{2} \mathrm{O}$ ).

PG can react with ammonium and alkaline carbonate to yield calcium carbonate $\left(\mathrm{CaCO}_{3}\right)$, ammonium and alkaline sulfate respectively. The general reaction can be expressed as following [12-15]:

$$
\begin{gathered}
\mathrm{CaSO}_{4} \cdot 2 \mathrm{H}_{2} \mathrm{O}+\mathrm{A}_{2} \mathrm{CO}_{3} \rightarrow \mathrm{CaCO}_{3}+\mathrm{A}_{2} \mathrm{SO}_{4}+2 \mathrm{H}_{2} \mathrm{O} \\
\text { with } \mathrm{A}=\mathrm{NH}_{4}, \mathrm{Na}, \mathrm{K} \text { and } \mathrm{Li}
\end{gathered}
$$

Also, the reaction of $\mathrm{PG}$ can with alkaline hydroxide 
produce calcium hydroxide $\left(\mathrm{Ca}(\mathrm{OH})_{2}\right)$ and alkaline sulfates, according to the following reaction $[16,17]$ :

$$
\begin{gathered}
\mathrm{CaSO}_{4} \cdot 2 \mathrm{H}_{2} \mathrm{O}+2 \mathrm{AOH} \rightarrow \mathrm{Ca}(\mathrm{OH})_{2}+\mathrm{A}_{2} \mathrm{SO}_{4}+2 \mathrm{H}_{2} \mathrm{O} \\
\text { with } \mathrm{A}=\mathrm{Li}, \mathrm{Na} \text { and } \mathrm{K}
\end{gathered}
$$

Several factors affect on these reactions (3 and 4), such as: (i) the nature of the PG used (sedimentary, igneous, sieved, purified...); (ii) the molar ratio between PG and reagents; (iii) the temperature and pressure of the mixture; and (iv) the duration of the conversion reaction [12-17].

In the recent years, certain researchers involved to convert PG by ammonium fluoride $\left(\mathrm{NH}_{4} \mathrm{~F}\right)$ according to the following reaction $[6,7,18]$ :

$$
\begin{gathered}
\mathrm{CaSO}_{4} \cdot 2 \mathrm{H}_{2} \mathrm{O}+2 \underset{2 \mathrm{H}_{2} \mathrm{O}}{\mathrm{NH}} \rightarrow \mathrm{CaF}_{2}+\left(\mathrm{NH}_{4}\right)_{2} \mathrm{SO}_{4}+ \\
\text {. }
\end{gathered}
$$

Generally, this process is more attract if effectively that the production of $\mathrm{NH}_{4} \mathrm{~F}$ is done by the neutralization of the recuperated hydrofluoric acid (HF) by ammonia at the plant site.

In the light of these processes (3,4 and 5), the purity of the obtained calcium compounds $\left(\mathrm{CaCO}_{3}, \mathrm{Ca}(\mathrm{OH})_{2}\right.$ and $\left.\mathrm{CaF}_{2}\right)$ are about 96, 95 and $93 \%$ respectively. These rational percentages are due to the presence of the insoluble impurities, which the most of them pass into the resulting calcium precipitates $[6,7$, 12-18]. For the radioactivity, the results of several works carried out on the radioactivity of $\mathrm{PG}$ and the resulting products show that these compounds could be considered as naturally occurring radioactive material (NORM). However, the sulfate salts recrystallized from the filtrates contain a very low amount of the toxic elements and the radionuclides [12, 19-21], which tolerate their use directly in various fields such as agriculture, cleaning products, paper industries.

In this work, we propose an environmental process which allows converting the Moroccan PG by $\mathrm{NaF}$ into $\mathrm{CaF}_{2}$ and sodium sulfate $\left(\mathrm{Na}_{2} \mathrm{SO}_{4}\right)$. The importance of this process comes from remedying of two major environmental problems, the first is related to the management of PG waste and the second concerns the reduction of the acid fluorine gases rejection into the atmosphere (greenhouse gasses emissions).

Due to its excellent physical and chemical properties, $\mathrm{CaF}_{2}$ is usually employed in building material, cement modification, crystalline fluorspar, Glass industry and metallurgy [22, 23], while, $\mathrm{Na}_{2} \mathrm{SO}_{4}$ can be used in the glass industry, detergents, pulp and paper. Kostick [24] has indicated that the price of $\mathrm{Na}_{2} \mathrm{SO}_{4}$ is $130-140$ \$/ton.

\section{MATERIAL AND METHODS}

The PG sample used in this work was taken from the fertilizer plant Maroc Phosphore (Jorf Lasfar near to El Jadida, Morocco). This PG is of dihydrate form and sedimentary origin. Sodium fluoride (min $98.5 \%$, Sigma Aldrich) was utilized as reactant.

The experimental protocol consists firstly to wash PG to eliminate some of the soluble impurities and suspension materials [2]. After that, about $103.3 \mathrm{~g}$ of this PG was dissolved in 1 liter of aqueous solution contained $0.6 \mathrm{M} / 1$ of $\mathrm{NaF}$. The reactional mixture was carried at room temperature and pressure under constant stirring (300 tr/min). After reaction duration of 90 minutes, the reactional mixture was filtered to obtain a whitish precipitate $\left(\mathrm{CaF}_{2}\right)$. This latter was dried in the oven at $105^{\circ} \mathrm{C}$, while the recrystallization of the recuperate filtrate yielded a transparent salt $\mathrm{Na}_{2} \mathrm{SO}_{4}$.

The different analyses carried out on the $\mathrm{PG}$ and the resulting compounds are realized by several techniques. The nature of mineral phases was identified by X-ray powder diffraction (Bruker D8 Advance Eco with $\mathrm{K} \alpha \mathrm{Cu}$ radiation). Infrared spectra were performed by Fourier transform infrared spectroscopy (Thermo Scientific Nicolet iS10 FT-IR Spectrometer) using ATR technique. The $\mathrm{Ca}, \mathrm{Na}, \mathrm{K}$ and $\mathrm{Ba}$ concentrations were determined by flame photometer (Jenway 500-731 Model PFP7). The sulfate concentration was determined by using gravimetric method after precipitation of $\mathrm{SO}_{4}{ }^{2-}$ under barium sulfate form. The contents of $\mathrm{P}_{2} \mathrm{O}_{5}$ and $\mathrm{F}$ were analyzed by spectrophotometer (Rayleigh VIS-7220 G/UV-9200) and ionometric method (fluoride ion selective electrode Tacussel TR 200) respectively after necessary calibration. The concentration of the other elements ( $\mathrm{Si}, \mathrm{Al}$, $\mathrm{Mg}$ and $\mathrm{Fe}$ ) was determined by inductively coupled plasma mass spectrometry (ICP-MS Model HP-4500). The hydration degrees of our samples were examined by thermogravimetric analysis (TGA) (DTG-60 type SHIMADZU). The morphology of PG and the obtained $\mathrm{CaF}_{2}$ was studied by scanning electron microscopy (SEM). Table 1 regrouped the listed materials and the different analyses carried out on the PG and the resulting compounds.

Table 1. List of materials and the different analyses carried out on the PG and the resulting compounds

\begin{tabular}{cc}
\hline \multicolumn{2}{c}{ Initial reactive and operator conditions } \\
\hline $\mathrm{PG}$ & $103.3 \mathrm{~g}$ \\
$\mathrm{NaF}$ & $25.2 \mathrm{~g}$ \\
Distilled water & $1 \mathrm{~L}$ \\
Stirring & $300 \mathrm{tr} / \mathrm{min}$ \\
Temperature & $25^{\circ} \mathrm{C}$ \\
Reaction time & 90 minutes \\
\hline \multicolumn{2}{c}{ Element Analyzed and Method used } \\
\hline Major Mineral & X-ray powder diffraction (XRD) \\
phases & Fourier transform infrared spectroscopy \\
Minor phases & (FTIR) \\
Morphology & Scanning electron microscopy (SEM) \\
$\mathrm{Ca}, \mathrm{Na}, \mathrm{K}$ and $\mathrm{Ba}$ & Flame photometer \\
$\mathrm{SO} 4^{2-}$ & Gravimetric method \\
$\mathrm{P}_{2} \mathrm{O}_{5}$ & spectrophotometer \\
$\mathrm{F}$ & Ionometric method \\
$\mathrm{Si}, \mathrm{Al}, \mathrm{Mg}$ and & Inductively coupled plasma mass spectrometry \\
$\mathrm{Fe}$ & (ICP-MS) \\
$\mathrm{H}_{2} \mathrm{O}$ & Thermogravimetric analysis (TGA) \\
\hline \multicolumn{2}{c}{}
\end{tabular}

\section{RESULTS AND DISCUSSION}

The XRD diffractogram of the PG sample is shown in Figure 1(a). It indicates well that this $P G$ is composed principally by gypsum $\left(\mathrm{CaSO}_{4} \cdot 2 \mathrm{H}_{2} \mathrm{O}, \mathrm{PDF} \mathrm{N}^{\circ}\right.$ : 00-033-0311) with a low quantity of quartz $\left(\mathrm{SiO}_{2}, \mathrm{PDF} \mathrm{N}^{\circ}\right.$ : 00-033-1161).

The results of the X-ray diffraction analyze carried out by Sebbahi et al. [25] and Ennaciri et al. [2] demonstrated the presence of a single phase: the dihydrate $\mathrm{CaSO}_{4} \cdot 2 \mathrm{H}_{2} \mathrm{O}$ in Moroccan PG (Jorf Lasfar) with the existence of a minority inert phase which is silica. Bourgier [26] justified the presence of two varieties of gypsum: the dihydrate and anhydrite. The presence of the latter is usually explained by the loss of water in the sample of calcium sulfate dihydrate during the 
evaporation step. Laganièrs [27] has identified in addition to the gypsum, the appearance of another phase which is $\mathrm{CaHPO}_{4}$. $2 \mathrm{H}_{2} \mathrm{O}$.
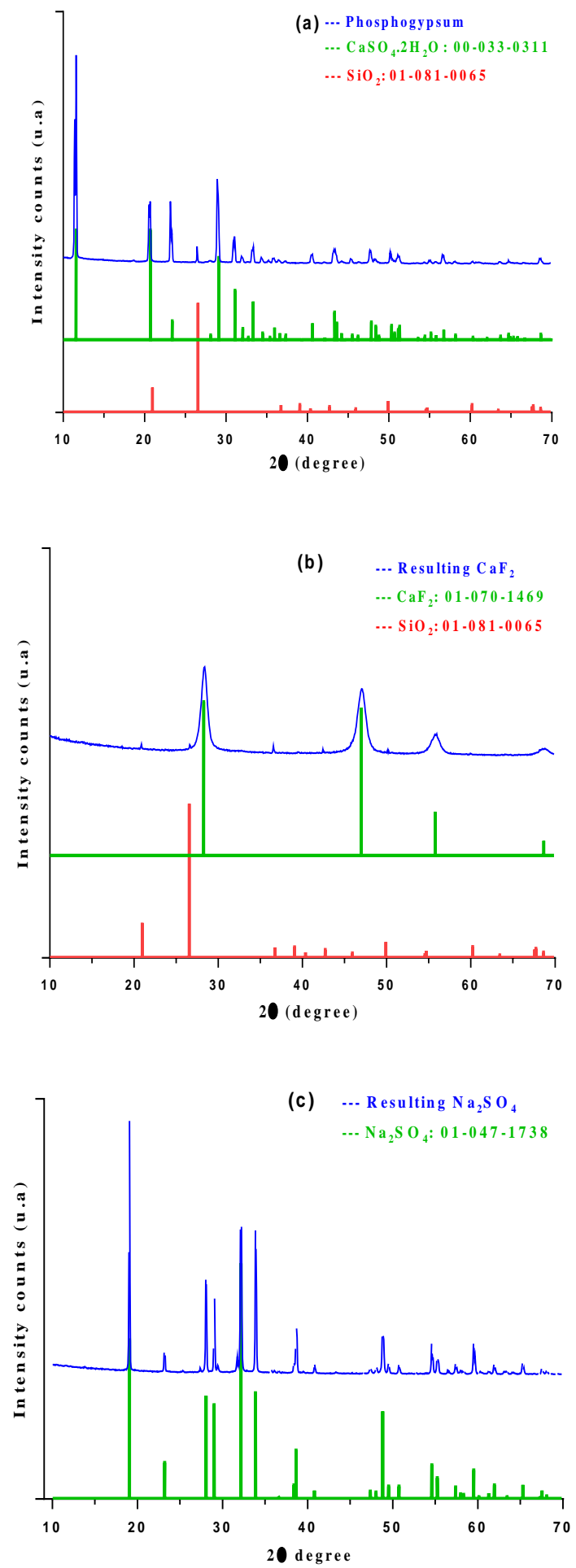

Figure 1. XRD patterns of the PG sample (a) [6], the precipitate $\mathrm{CaF}_{2}$ (b) and the salt $\mathrm{Na}_{2} \mathrm{SO}_{4}$ (c)

After total dissolution of PG sample in stochiometric $\mathrm{NaF}$ solution, the resulting precipitate (Figure 1(b)) corresponds well to calcium fluoride $\left(\mathrm{CaF}_{2}\right.$, PDF $\mathrm{N}^{\circ}$ : 01-070-1469). Generally, the formation of $\mathrm{CaF}_{2}$ and $\mathrm{Na}_{2} \mathrm{SO}_{4}$ during the conversion of $\mathrm{PG}$ can be explained by the following reaction:

$$
\mathrm{CaSO}_{4} \cdot 2 \mathrm{H}_{2} \mathrm{O}+2 \mathrm{NaF} \rightarrow \mathrm{CaF}_{2}+\mathrm{Na}_{2} \mathrm{SO}_{4}+2 \mathrm{H}_{2} \mathrm{O}
$$

Because of the large difference between the solubility of $\mathrm{PG}$ $\left(\mathrm{K}_{\mathrm{ps}}=3.14 \times 10^{-5}\right.$ at $\left.25^{\circ} \mathrm{C}\right)$ and $\mathrm{CaF}_{2}\left(\mathrm{~K}_{\mathrm{ps}}=3.45 \times 10^{-11}\right.$ at $\left.25^{\circ} \mathrm{C}\right)$, the reaction (6) moves towards the precipitation of $\mathrm{CaF}_{2}$ and the formation of $\mathrm{Na}_{2} \mathrm{SO}_{4}$

Ennaciri et al. [6, 7] and Douahem et al. [28] show that the $\mathrm{XRD}$ diffractograms of $\mathrm{CaF}_{2}$ prepared from the $\mathrm{PG}$ conversion by the different methods provided the same peaks.

Figure 1(c) shows the diffractogram of the recrystallized salt. It is clear that the diffractogram of this salt presents almost the same peaks of the sodium sulfate $\left(\mathrm{Na}_{2} \mathrm{SO}_{4}\right.$, PDF $\mathrm{N}^{\circ}$ : 01047-1738). A comparison between the XRD diffractograms of $\mathrm{Na}_{2} \mathrm{SO}_{4}$ recovered from the $\mathrm{PG}$ conversion by $\mathrm{Na}_{2} \mathrm{CO}_{3}$ and $\mathrm{NaOH}$ showed also the similar peaks $[14,17]$.

PG and obtained products were also examined by FTIR absorption. For the PG, similar bands with pure gypsum are clearly observed (Figure 2(a)) [2, 14].

The principal bands of this sample are attributed to the water and sulfate ions. The bands in region 3392-3508 and $1682 ; 1619 \mathrm{~cm}^{-1}$ correspond to water $v \mathrm{H}_{2} \mathrm{O}$ and $\delta \mathrm{H}_{2} \mathrm{O}$ respectively. For the sulfate ions, the bands appeared at 1101 and $1003 \mathrm{~cm}^{-1}$ are assigned to the symmetric and asymmetric stretching of $\mathrm{SO}_{4}{ }^{2-}$ respectively. The two bands observed at 666 and $598 \mathrm{~cm}^{-1}$ correspond to the bending of $\mathrm{SO}_{4}{ }^{2-}[2,14-$ 17].

In other hand, the precipitate $\mathrm{CaF}_{2}$ (Figure 2(b)) does not absorb IR radiations between 500 and $4000 \mathrm{~cm}^{-1}$. The work carried out by Pandurangappa et al. [29] and Tahvildari et al. [30], indicate the same results for $\mathrm{CaF}_{2}$ nanoparticles synthesized by both co-precipitation and hydrothermal methods. However, Seshadri et al. [31] indicated that the infrared spectrum of molecular species formed on vaporizing solid $\mathrm{CaF}_{2}$ trapped in a solid krypton matrix at $20 \mathrm{~K}$, shows the appearance of bands at 550, 520, 485, 365 and $162 \mathrm{~cm}^{-1}$.

The other auxiliary bands appear at 3391-3505 and 1642 $\mathrm{cm}^{-1}$ are attributed to the adsorbed water $v \mathrm{H}_{2} \mathrm{O}$ and $\delta \mathrm{H}_{2} \mathrm{O}$ respectively, while the bands at 632 and $1063-1213 \mathrm{~cm}^{-1}$ are assigned to symmetric and antisymmetric stretching of Si-O$\mathrm{Si}$ respectively [32]. The band appearing at $872 \mathrm{~cm}^{-1}$ corresponds to symmetric stretching of $\mathrm{HPO}_{4}{ }^{2-}$ [26].

The infrared spectrum of the recrystallized salt (Figure 2(c)) confirms the characteristic bands of pure $\mathrm{Na}_{2} \mathrm{SO}_{4}$. The bands at 1,098 and $609 \mathrm{~cm}^{-1}$ are assigned to asymmetric stretching and asymmetric bending of $\mathrm{SO}_{4}^{2-}$ respectively [14]. Periasamy et al. [33] have mentioned that the characteristic bands of the pure $\mathrm{Na}_{2} \mathrm{SO}_{4}$ can be observed at 1,123 and $615 \mathrm{~cm}^{-1}$.

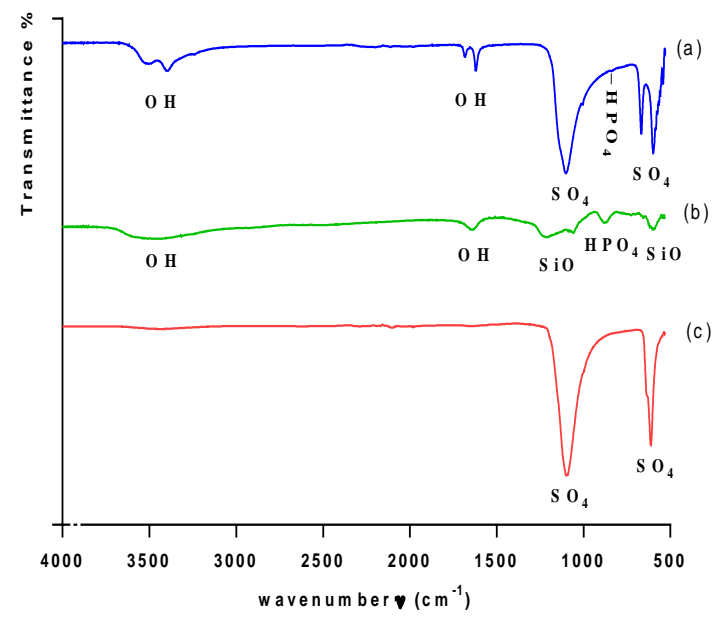

Figure 2. FTIR spectra of the PG sample (a), the precipitate $\mathrm{CaF}_{2}$ (b) and the salt $\mathrm{Na}_{2} \mathrm{SO}_{4}$ (c) 
Table 2 regroups the different vibration band frequencies and assignments of the PG and the obtained products.

Table 2. FTIR frequencies of the PG sample and the finals products

\begin{tabular}{|c|c|c|c|c|}
\hline \multirow{2}{*}{\multicolumn{2}{|c|}{$\begin{array}{c}\text { Assignment } \\
\text { Ion /Molecule }\end{array}$}} & \multicolumn{3}{|c|}{ Wave number $v\left(\mathrm{~cm}^{-1}\right)$} \\
\hline & & \multirow{2}{*}{$\begin{array}{c}\begin{array}{c}\text { Phospho- } \\
\text { gypsum (a) }\end{array} \\
3392-3508\end{array}$} & \multirow{2}{*}{$\begin{array}{c}\begin{array}{c}\text { Precipitate } \\
\text { CaF2 }_{\text {(b) }}\end{array} \\
3391-3505\end{array}$} & \multirow{2}{*}{$\begin{array}{c}\begin{array}{c}\text { Salt } \\
\mathrm{Na}_{2} \mathrm{SO}_{4}(\mathrm{c})\end{array} \\
--\end{array}$} \\
\hline $\mathrm{H}_{2} \mathrm{O}$ & $v \mathrm{O}-\mathrm{H}(\mathrm{St})$ & & & \\
\hline & $\begin{array}{c}\delta \mathrm{H}-\mathrm{O}-\mathrm{H} \\
\text { (D) }\end{array}$ & $1682 ; 1619$ & 1642 & -- \\
\hline \multirow[t]{3}{*}{$\mathrm{SO}_{4}{ }^{2}$} & $\begin{array}{c}v_{3} \mathrm{SO}_{4}{ }^{2-} \\
(\mathrm{ASt})\end{array}$ & 1101 & -- & 1098 \\
\hline & $\begin{array}{c}v_{1} \mathrm{SO}_{4}{ }^{2-} \\
(\mathrm{SSt})\end{array}$ & 1003 & -- & -- \\
\hline & $\begin{array}{l}v_{4} \mathrm{SO}_{4}{ }^{2-} \\
\text { (B) }\end{array}$ & $666 ; 598$ & -- & 609 \\
\hline \multirow[t]{2}{*}{$\begin{array}{l}\mathrm{HPO} \\
4^{2-}\end{array}$} & $\begin{array}{l}v \mathrm{P}-\mathrm{O}(\mathrm{H}) \\
\quad(\mathrm{SSt})\end{array}$ & -- & 872 & -- \\
\hline & $\begin{array}{c}v \text { P-O-H } \\
(\mathrm{Dhp})\end{array}$ & 835 & -- & -- \\
\hline \multirow[t]{2}{*}{$\mathrm{SiO}_{2}$} & $\begin{array}{c}v \mathrm{Si}-\mathrm{O}-\mathrm{Si} \\
\quad(\mathrm{ASt})\end{array}$ & $1063-1213$ & -- & -- \\
\hline & $\begin{array}{c}v \mathrm{Si}-\mathrm{O}-\mathrm{Si} \\
\quad(\mathrm{SSt})\end{array}$ & -- & 632 & -- \\
\hline
\end{tabular}

(St): stretch region; (D): deformation; (ASt): asymmetric stretching;

(SSt): symmetric stretching; (B): bending; (Dhp): deformation hors plan.

Figure 3(a,b) shows the SEM images of PG and $\mathrm{CaF}_{2}$ respectively. We observe that the morphological structure of $\mathrm{PG}$ is tabular with a size grading from 5 to $30 \mu \mathrm{m}[2,15]$. For the obtained $\mathrm{CaF}_{2}$, the morphological results reveal that the powder is formed by polycrystalline agglomerates of size less than $2 \mu \mathrm{m}$.

Based on the obtained results, the reaction (6) remains an efficient procedure for to preparing relatively pure $\mathrm{CaF}_{2}$ from $\mathrm{PG}$ and $\mathrm{NaF}$. In addition, $\mathrm{Na}_{2} \mathrm{SO}_{4}$ recuperated by this process is economically attractive compared with other process such as Mannheim process (reaction of $\mathrm{NaCl}$ with sulfuric acid at $\left.700^{\circ} \mathrm{C}\right)[34]$.
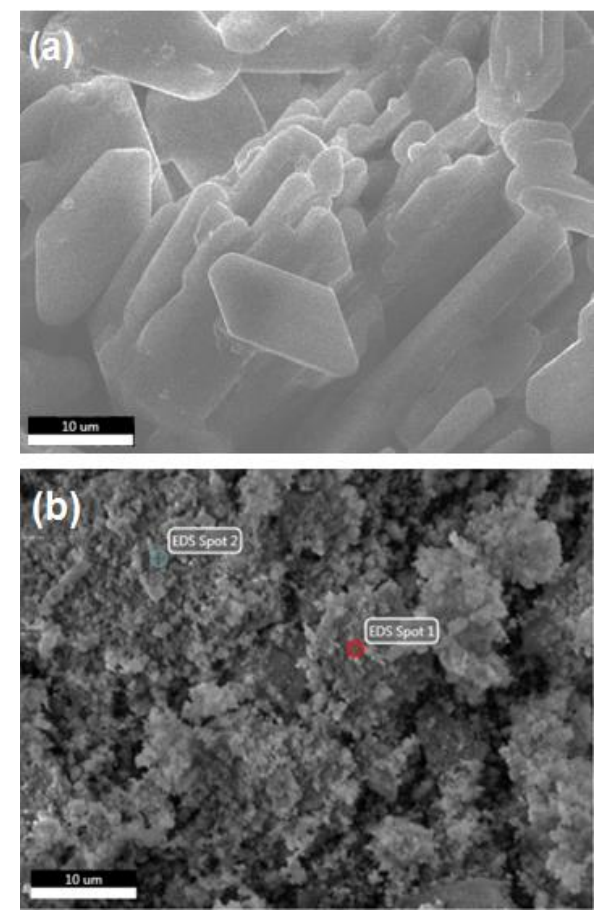

Figure 3. SEM images of the PG (a) and the obtained $\mathrm{CaF}_{2}$ (b)
Table 3 represents the results of the chemical analysis of the PG sample and the obtained $\mathrm{CaF}_{2}$ and $\mathrm{Na}_{2} \mathrm{SO}_{4}$. The results described previously by XRD and FTIR techniques are in agreement with the chemical analysis of the $\mathrm{PG}$ and the resulting compounds. Generally, the major impurities which contain PG are totally transformed into the precipitate $\mathrm{CaF}_{2}$.

Table 3. Chemical composition of the PG and the finals products

\begin{tabular}{cccc}
\hline $\begin{array}{c}\text { Major elements } \\
(\%)\end{array}$ & $\begin{array}{c}\text { Phospho- } \\
\text { gypsum (a) }\end{array}$ & $\begin{array}{c}\text { Precipitate } \\
\mathbf{C a F}_{2}(\mathbf{b})\end{array}$ & $\begin{array}{c}\text { Salt } \\
\mathbf{N a}_{2} \mathbf{S O}_{4}(\mathbf{c})\end{array}$ \\
\hline $\mathrm{CaO}$ & 31.28 & $50.41^{(1)}$ & 0.42 \\
$\mathrm{SO}_{3}$ & 44.69 & 0.41 & 55.18 \\
$\mathrm{~F}$ & 0.67 & 43.34 & 0.62 \\
$\mathrm{Na}_{2} \mathrm{O}$ & 0.26 & 0.61 & 43.38 \\
$\mathrm{~K}_{2} \mathrm{O}$ & 0.02 & 0.04 & -- \\
$\mathrm{P}_{2} \mathrm{O}_{5}$ & 1.11 & 2.35 & - \\
$\mathrm{SiO}_{2}$ & 0.96 & 2.21 & 0.39 \\
$\mathrm{Al}_{2} \mathrm{O}_{3}$ & 0.16 & 0.29 & -- \\
$\mathrm{MgO}^{\mathrm{Fe}} \mathrm{O}_{3}$ & 0.02 & 0.04 & -- \\
$\mathrm{H}_{2} \mathrm{O}$ & 0.02 & 0.03 & -- \\
$\mathrm{Ba}(\mathrm{ppm})$ & 20.58 & 0.26 & -- \\
\hline
\end{tabular}

(1): Expressed as \% Ca.

The PG sample used in this study contains about $96.5 \%$ of $\mathrm{CaSO}_{4} \cdot 2 \mathrm{H}_{2} \mathrm{O}$. The principal impurities are $\mathrm{P}_{2} \mathrm{O}_{5}, \mathrm{SiO}_{2}$ and $\mathrm{Al}_{2} \mathrm{O}_{3}, \mathrm{MgO}, \mathrm{Fe}_{2} \mathrm{O}_{3}, \mathrm{Na}_{2} \mathrm{O}$ and $\mathrm{K}_{2} \mathrm{O}$ in lesser amounts. The presence of these impurities in $\mathrm{PG}$ can be attributed to the inattacked phosphate rock, the clay, the insoluble complexes $\left(\mathrm{Na}_{2} \mathrm{SiF}_{6}, \mathrm{Na}_{3} \mathrm{AlF}_{6}, \mathrm{~K}_{3} \mathrm{AlF}_{6}, \mathrm{MgSiF}_{6} .6 \mathrm{H}_{2} \mathrm{O} \ldots\right)$ and the ions $\left(\mathrm{FPO}_{3}^{2-}, \mathrm{HPO}_{4}^{2-}, \mathrm{Ba}^{2+} \ldots\right)$ substituting $\mathrm{Ca}^{2+}$ or $\mathrm{SO}_{4}^{2}$ in $\mathrm{CaSO}_{4} \cdot 2 \mathrm{H}_{2} \mathrm{O}[1,2]$.

Generally, the chemical composition of our PG sample remains almost the same of the other sedimentary Mediterranean PGs (Tunisian, Algerian, Egyptian...). Contrary, the chemical composition of this PG sample differs to those of igneous PGs (Poland, Brazilian...), which contain higher concentration of water, fluorine... [1, 2, 21, 26].

The chemical composition of resulting precipitate represents about $93.7 \%$ of $\mathrm{CaF}_{2}(50.41 \%$ as $\mathrm{Ca}$ and $43.34 \%$ as F). This degree of purity can be explained by the presence of impurities, which are nearly doubled when PG is converted into $\mathrm{CaF}_{2}$. Compared with other work realized by Douahem et al. [28], the purity of $\mathrm{CaF}_{2}$ obtained from the conversion of the Tunisian PG by $\mathrm{NaF}$ is about $98 \%$. This can be explained by the purity of the Tunisian $\mathrm{PG}$ and $\mathrm{NaF}$ used in this work. Ennaciri et al. [6, 7] have showed that the purity of $\mathrm{CaF}_{2}$ obtained from the conversion of Moroccan PG by mixture of $\mathrm{NH}_{3} / \mathrm{HF}$ and $\mathrm{NaF} / \mathrm{HF}$ are 93.4 and $93.0 \%$ respectively.

The important impurities in the precipitate $\mathrm{CaF}_{2}$ are $\mathrm{P}_{2} \mathrm{O}_{5}$ $(2.35 \%)$ and $\mathrm{SiO}_{2}(2.21 \%)$. These insoluble impurities rest inert or in attacked during the PG conversion and remains in the precipitate $[6,7,13,14]$. The existence of sulfur in the precipitate is due to $\mathrm{Na}_{2} \mathrm{SO}_{4}$ traces, which are adsorbed in the surface of $\mathrm{CaF}_{2}$ particle through the filtration. The precipitate contained also a low amount of $\mathrm{Al}, \mathrm{Mg}$ and $\mathrm{Fe}$, which come from clays. Generally, the content of these impurities is similar to that reported in other $\mathrm{CaF}_{2}$ obtained from the $\mathrm{PG}$ conversion $[6,7]$.

Regarding the trace elements and the radioelements, the pervious researches focused on PG conversion, mentioned that these elements are found with resulting calcium precipitates, while the filtrate of the dissolution process rest uncontaminated from these elements $[6,7,12,19,21]$. 
Fluorspar is used in steel manufacture and other metallurgical operations principally to ensure the desired fluidity in the slag and to assist in refining the bath of molten metal but without changing the basicity or acidity of the slag. Also, the addition of this matter permits removing simultaneously the main impurities ( $, \mathrm{P}, \mathrm{N}, \mathrm{O}, \mathrm{H} \ldots$ ) out of metals in the highest level. Generally, the majority of the researches related to the use of fluorspar in metallurgy insists that this fluorspar should contain not less than $85 \% \mathrm{CaF}_{2}$. Certain researchers added other norms such as content of $\mathrm{Si}, \mathrm{S}$ and $\mathrm{Ba}$ (see Table 4). Also, even when conforming to or excelling these chemical standards, must be available in quantity and preferably in adequate physical form [22, 23, 3539].

Table 4. Chemical composition of the obtained $\mathrm{CaF}_{2}$ compared with the chemical standards for used in metallurgy

\begin{tabular}{|c|c|c|c|c|c|}
\hline Content $(\%)$ & & $\mathrm{CaF}_{2}$ & $\mathrm{SiO}_{2}$ & $\mathrm{SO}_{3}$ & $\mathbf{B a}$ \\
\hline \multirow{4}{*}{$\begin{array}{c}\mathrm{CaF}_{2} \text { obtained from the } \\
\text { PG conversion }\end{array}$} & This work & 93.7 & 2.21 & 0.41 & 0.00 \\
\hline & [6] & 93.4 & 2.13 & 0.26 & 0.00 \\
\hline & [7] & 93.0 & 2.01 & 0.46 & 0.00 \\
\hline & [28] & 98 & -- & -- & -- \\
\hline \multirow{4}{*}{$\begin{array}{l}\text { Standard to use } \\
\text { fluorspar in metallurgy }\end{array}$} & [35] & $85<$ & -- & -- & -- \\
\hline & [36] & $85<$ & $<5$ & -- & -- \\
\hline & [22] & $85<$ & $<5$ & $<0.75$ & -- \\
\hline & [23] & $85<$ & $10-15$ & $<2$ as $\mathrm{E}$ & $\mathrm{BSO}_{4}$ \\
\hline
\end{tabular}

Based on these requirements and the results of chemical analyses of the precipitate, we conclude that the resulting $\mathrm{CaF}_{2}$ can be utilized directly in this metallurgical industry. Also, the use of the obtained $\mathrm{CaF}_{2}$ as synthetic fluorspar can contribute to conserve the naturel reserves of fluorite.

The recrystallized salt is characterized by high amount of sodium $\left(43.38 \%\right.$ as $\left.\mathrm{Na}_{2} \mathrm{O}\right)$ and sulfur $\left(55.18 \%\right.$ as $\left.\mathrm{SO}_{3}\right)$. The existence of major impurities $(\mathrm{Ca}, \mathrm{Si}$ and $\mathrm{F})$ in this salt are originally reported to the presence of these elements in $\mathrm{NaF}$ reagent or to the fine particle of $\mathrm{CaF}_{2}$, which passed into salt during the filtration. Generally, the obtained salt $\mathrm{Na}_{2} \mathrm{SO}_{4}$ is a relatively pure product, which could be used directly in the industry of detergent, glass, pulp and paper [17].

\section{CONCLUSION}

In this work, we have elaborated a feasible process which allows converting PG waste by using the sodium fluoride. This process is realized in aqueous solution and leads to zero-waste with recovery of interesting products $\mathrm{CaF}_{2}$ and $\mathrm{Na}_{2} \mathrm{SO}_{4}$.

The total conversion of $\mathrm{PG}$ is achieved at room temperature for an exact stoichiometric proportion of $\mathrm{PG}$ and $\mathrm{NaF}$ during a time reaction of 90 minutes.

The environmental interest of this process is reducing the quantity of PG rejected and minimizing the emission of fluorine gas. For a numerical approach, about $15 \mathrm{Mt}$ of PG (the annual quantities of $\mathrm{PG}$ generated by the fertilizer industry of Morocco) can be treated by $7.325 \mathrm{Mt}$ of $\mathrm{NaF}$ to obtain 6.809 $\mathrm{Mt}$ of $\mathrm{CaF}_{2}$ and $12.383 \mathrm{Mt}$ of $\mathrm{Na}_{2} \mathrm{SO}_{4}$.

The purity of $\mathrm{Na}_{2} \mathrm{SO}_{4}$ salt tolerates it to be commercialized or used in detergent industry. Since the resulting $\mathrm{CaF}_{2}$ obtained is considered as a material which can be applied directly in the metallurgical industry.

In the economical approach, the PG conversion by $\mathrm{NaF}_{2}$ does not require any difficult operation (simple filtration, room temperature) for recuperating $\mathrm{CaF}_{2}$ and $\mathrm{Na}_{2} \mathrm{SO}_{4}$, but the cost analysis of this process rest generally not good. The cost effectiveness is realizable only in case of the environment protection (subsidy from the environment protection fund).

\section{REFERENCES}

[1] Ennaciri, Y., Bettach, M., Cherrat, A., Zdah, I., El Alaoui-Belghiti, H. (2020). Study of the physicalchemical properties of the Moroccan phosphogypsum: A review. Matériaux et Techniques, 108(2): 207-222. https://doi.org/10.1051/mattech/2020029

[2] Ennaciri, Y., Zdah, I., El Alaoui-Belghiti, H., Bettach, M. (2019). Characterization and purification of waste phosphogypsum to make it suitable for use in the plaster and the cement industry. Chemical Engineering Communications, 207(3): 382-392. https://doi.org/10.1080/00986445.2019.1599865

[3] El Zrelli, R., Rabaoui, L., Daghbouj, N., Abda, H., Castet, S., Josse, C., Van Beek, P., Souhaut, M., Michel, S., Bejaoui, N., Courjault-Radé, P. (2018). Characterization of phosphate rock and phosphogypsum from Gabes phosphate fertilizer factories (SE Tunisia): High mining potential and implications for environmental protection. Environmental Science and Pollution Research, 25(15): 14690-14702. https://doi.org/10.1007/s11356-018-16484

[4] Mohr, A.C., Obrecht, R.P., Campbell, R.G., Messenger, A.L. (1966). Process for recovering strong HF from phosphate rock digestion processes. Patent US3257167.

[5] Lailach, G., Bulan, A., Buss, G. (2001). Process for the preparation of sodium fluoride. Patent US6251358.

[6] Ennaciri, Y., Bettach, M., El Alaoui-Belghiti, H. (2020). Conversion of Moroccan phosphogypsum waste into nano-calcium fluoride and sodium hydrogen sulfate monohydrate. Journal of Material Cycles and Waste Management, 22: 2039-2047. https://doi.org/10.1007/s10163-020-01088-1

[7] Ennaciri, Y., Bettach, M., El Alaoui-Belghiti, H. (2020). Recovery of nano-calcium fluoride and ammonium bisulphate from phosphogypsum waste. International Journal of Environmental Studies, 77(2): 297-306. https://doi.org/10.1080/00207233.2020.1737426

[8] Wang, J. (2020). Utilization effects and environmental risks of phosphogypsum in agriculture: A review. Journal of Cleaner Production, 276: 123337. https://doi.org/10.1016/j.jclepro.2020.123337

[9] Nguyen, V.B. (2019). Using refined phosphogypsum to replace natural gypsum in Portland cement production in Vietnam. International Journal of Sustainable Energy and Environmental Research, 8(1): 62-69. https://doi.org/10.18188/journal.13.2019.61.62.69

[10] Zheng, D., Ma, L., Wang, R., Yang, J., Dai, Q. (2018). Decomposing properties of phosphogypsum with iron addition under two-step cycle multi-atmosphere control in fluidized bed. Waste Management and Research, 36(2): 183-193. https://doi.org/10.1177/0734242X17748362

[11] Aagli, A., Tamer, N., Atbir, A., Boukbir, L., El Hadek, M. (2005). Conversion of phosphogypsum to potassium sulfate, Part I. The effect of temperature on the solubility of calcium sulfate in concentrated aqueous chloride solutions. Journal of Thermal Analysis and Calorimetry, 82: 395-399. https://doi.org/10.1007/s10973-005-0908-y

[12] Burnett, W.C., Schultz, M.K., Hull, C.D. (1996). 
Radionuclide flow during the conversion of phosphogypsum to ammonium sulfate. Journal of Environmental Radioactivity, 32(1-2): 33-51. http://dx.doi.org/10.1016/0265-931X(95)00078-O

[13] Ennaciri, Y., El Alaoui-Belghiti, H., Bettach, M. (2019). Comparative study of $\mathrm{K}_{2} \mathrm{SO}_{4}$ production by wet conversion from phosphogypsum and synthetic gypsum. Journal of Materials Research and Technology, 8(3): 2586-2596. https://doi.org/10.1016/j.jmrt.2019.02.013

[14] Ennaciri, Y., Bettach, M., Cherrat, A., Zegzouti, A. (2016). Conversion of phosphogypsum to sodium sulfate and calcium carbonate in aqueous solution. Journal of Materials and Environmental Science, 7(6): 1925-1933.

[15] Ennaciri, Y., Bettach, M. (2018). Procedure to convert phosphogypsum waste into valuable products. Materials and Manufacturing Processes, 33(16): 1727-1733. https://doi.org/10.1080/10426914.2018.1476763

[16] El Aloui Belghiti, H., Zdah, I., Ennaciri, Y., El Ouatib, R., Bettach, M. (2021). Valorization of phosphogypsum waste as $\mathrm{K}_{2} \mathrm{SO}_{4}$ fertilizer and portlandite. International Journal of Environment and Waste Management. https://doi.org/10.1504/IJEWM.2021.10029039

[17] El Alaoui-Belghiti, H., Bettach, M., Zdah, I., Ennaciri, Y., Assaoui, J., Zegzouti, A. (2020). Optimization of conditions to convert phosphogypsum into $\mathrm{Ca}(\mathrm{OH})_{2}$ and $\mathrm{Na}_{2} \mathrm{SO}_{4}$. Moroccan Journal of Chemistry, 8(3): 594-605.

[18] Zhou, L. (2018). Preparation of calcium fluoride using phosphogypsum by orthogonal experiment. Open Chemistry, $16(1)$ : 864-868. https://doi.org/10.1515/chem-2018-0093

[19] Contreras, M., Pérez-López, R., Gázquez, M.J., MoralesFlórez, V., Santos, A., Esquivias, L., Bolívar, J.P. (2015). Fractionation and fluxes of metals and radionuclides during the recycling process of phosphogypsum wastes applied to mineral $\mathrm{CO}_{2}$ sequestration. Waste Management, 45: 412-419. https://doi.org/10.1016/j.wasman.2015.06.046

[20] Mulopo, J., Ikhu-Omoregbe, D. (2012). Phosphogypsum conversion to calcium carbonate and utilization for remediation of acid mine drainage. Journal of Chemical Engineering and Process Technology, 3(2): 2-6. http://dx.doi.org/10.4172/2157-7048.1000129

[21] Zemni, S., Hajji, M., Triki, M., M'nif, A., Hamzaoui, A.H. (2018). Study of phosphogypsum transformation into calcium silicate and sodium sulfate and their physicochemical characterization. Journal of Cleaner Production, 198: 874-881. https://doi.org/10.1016/j.jclepro.2018.07.099

[22] Górecki, H.J. (1994). Utilization of Fluorine from Phosphate Fertilizer Plants. In: Hodge, C.A., (1994). Pollution control in fertilizer production, CRC Press, pp. 299-335

[23] Kowalski, Z., Paszek, A. (1999). Production of synthetic fluorspar from waste calcium fluoride slurry. Polish Journal of Environmental Studies, 8: 125-128.

[24] Kostick, D.S. (2013). Sodium Sulfate. US Geological Survey, Mineral Commodity Summaries, pp. 150-151.

[25] Sebbahi, S., Chameikh, M.L.O., Sahban, F., Aride, J., Benarafa, L., Belkbir, L. (1997). Thermal behaviour of Moroccan phosphogypsum. Thermochimica Acta, 302: 69-75.

[26] Bourgier, V. (2007). Influence des ions monohydrogénophosphates et fluorophosphates sur les

propriétés des phosphogypses et la réactivité des phosphoplâtres.

[27] Laganièrs, D. (2002). Caractérisation, stabilisation et valorisation des phosphogypses marocains.

[28] Douahem, H., Hammi, H., Hamzaoui, A.H., M'nif, A. (2016). Modeling and optimization of phosphogypsum transformation into calcium fluoride using experimental design methodology. Journal of the Tunisian Chemical Society, 18: 106-113.

[29] Pandurangappa, C., Lakshminarasappa, B.N., Nagabhushana, B.M. (2010). Synthesis and characterization of $\mathrm{CaF}_{2}$ nanocrystals. Journal of Alloys and Compounds, 489: 592-595. https://doi.org/10.1016/j.jallcom.2009.09.118

[30] Tahvildari, K., Esmaeili, M., Ghammamy, S. Nabipour, H. (2012). $\mathrm{CaF}_{2}$ nanoparticles: Synthesis and characterization. International Journal of Nano Dimension, 2(4): 269-273.

[31] Calder, V., Mann, D.E., Seshadri, K.S., Allavena, M., White, D. (1969). Geometry and Vibrational Spectra of Alkaline Earth Dihalides. II. $\mathrm{CaF}_{2}, \mathrm{SrF}_{2}$, and $\mathrm{BaF}_{2}$. The Journal of Chemical Physics, 51(1): 2093-2099. http://dx.doi.org/10.1063/1.1672304

[32] Almeida, R.M., Pantano, C.G. (1990). Structural investigation of silica gel films by infrared spectroscopy. Journal of Applied Physics, 68(8): 4225-4232. https://doi.org/10.1063/1.346213

[33] Periasamy, A., Muruganand, S., Palaniswamy, M. (2009). Vibrational studies of $\mathrm{Na}_{2} \mathrm{SO}_{4}, \mathrm{~K}_{2} \mathrm{SO}_{4}, \mathrm{NaHSO}_{4}$ and $\mathrm{KHSO}_{4}$ crystals. Rasayan Journal of Chemistry, 2(4): 981-989.

[34] Emil Raymond, R. (1974). James Albert, K. (ed.). Riegel's Handbook of Industrial Chemistry (7th ed.). New York: Van Nostrand Reinhold, p. 132. ISBN 9780442243470.

[35] Hameed, Z.A., Saleem, J., Hussain, S.S., Ghani, A.A., Lal, H. (2016). Characterization of Pakistani fluorspar for metallurgical slag making application. 1st International Conference on "Advance Materials \& Process Engineering". At: NED University of Engineering, Karachi, Pakistan/Professor Dr. Muhammad Tufail Convener, 165: 165-171. https://doi.org/10.13140/RG.2.1.3166.6320

[36] Abbott, C.F., Anderson, C.O. (1940). Metallurgical flux and method of producing it. Patent US2220385.

[37] Stoephasius, J.C., Reitz, J., Friedrich, B. (2007). ESR refining potential for titanium alloys using a $\mathrm{CaF}_{2}$-based active slag. Advanced Engineering Materials, 9(4): 246252. https://doi.org/10.1002/adem.200700009

[38] Liu, J., Kobayashi, Y. (2017). Desulfurizing ability of the $\mathrm{CaO}_{\text {satd. }}-\mathrm{CaCl}_{2}-\mathrm{CaF}_{2}$ slags. Metallurgical and Materials Transactions B, 48(2): 1108-1113. https://doi.org/10.1007/s11663-016-0890-8

[39] Abdeyazdan, H., Edris, H., Abbasi, M.H. (2011). The effect of $\mathrm{CaF}_{2}$ content in hot metal pretreatment flux based on lime. International Journal of ISSI, 8(2): 5-8.

\section{NOMENCLATURE}

PG

FSA

AHF phosphogypsum

hexafluosilicic acid $\mathrm{H}_{2} \mathrm{SiF}_{6}$ anhydrous hydrofluoric acid HF 